\title{
Candidate gene discovery procedure after follow-up confirmatory analyses of candidate regions of interests for Alzheimer's disease in the NIMH sibling dataset
}

\author{
Tesfaye M. Baye ${ }^{\mathrm{a}, \mathrm{b}, *}$, Rodney T. Perry ${ }^{\mathrm{b}}$, Howard W. Wiener ${ }^{\mathrm{b}}$, Zuomin Chen ${ }^{\mathrm{b}}$, Lindy E. Harrell ${ }^{\mathrm{c}}$ and \\ Rodney C.P. Go ${ }^{\mathrm{b}}$ \\ ${ }^{a}$ Section on Statistical Genetics, Department of Biostatistics, University of Alabama at Birmingham, Birmingham, \\ AL 35294, USA \\ ${ }^{\mathrm{b}}$ Department of Epidemiology and International Health, University of Alabama at Birmingham, Birmingham, AL \\ 35294, USA \\ ${ }^{\mathrm{c}}$ Department of Neurology, University of Alabama at Birmingham, Birmingham, AL 35294, USA
}

\begin{abstract}
The objective of this research was to develop a procedure to identify candidate genes under linkage peaks confirmed in a follow-up of candidate regions of interests (CRIs) identified in our original genome scan in the NIMH Alzheimer's diseases (AD) Initiative families (Blacker et al. [1]). There were six CRIs identified that met the threshold of multipoint lod score (MLS) of $\geqslant 2.0$ from the original scan. The most significant peak (MLS $=7.7$ ) was at $19 \mathrm{q} 13$, which was attributed to APOE. The remaining CRIs with 'suggestive' evidence for linkage were identified at 9q22, 6q27, 14q22, 11q25, and 3p26. We have followed up and narrowed the 9q22 CRI signal using simple tandem repeat (STR) markers (Perry et al. [2]). In this confirmatory project, we have followed up the 6q27, 14q22, 11q25, and 3p26 CRIs with a total of 24 additional flanking STRs, reducing the mean interval marker distance (MID) in each CRI, and substantially increase in the information content (IC). The linkage signals at 6q27, 14q22 and 11q25 remain 'suggestive', indicating that these CRIs are promising and worthy of detailed fine mapping and assessment of candidate genes associated with AD.

We have developed a bioinformatics approach for identifying candidate genes in these confirmed regions based on the Gene Ontology terms that are annotated and enriched among the systematic meta-analyzed genes, confirmed by at least three case-control samples, and cataloged in the "AlzGene database" as potential Alzheimer disease susceptibility genes (http://www.alzgene.org).
\end{abstract}

Keywords: Alzheimer, linkage, QTL, STR, SNP, Genomic scan, Candidate gene, bioinformatics, gene ontology, GO, Alzforum, Alzgene database

\section{Introduction}

The most common form of dementia among aging people is Alzheimer's disease (AD), which involves

* Corresponding author: Tesfaye M. Baye, Section on Statistical Genetics, Department of Biostatistics, RPHB 327, University of Alabama at Birmingham, Birmingham, AL 35294-0022, USA. Tel.: +1 205975 9273; Fax: +1 205975 2540; E-mail: tmersha@uab.edu. the cerebral cortex and hippocampus which control thought, memory and language. Pathologically, AD is characterized by neurofibrillary tangles found in the neurons and the deposition of $\beta$-amyloid $(\mathrm{A} \beta)$ within senile plaques and cerebral blood vessels, resulting in the loss of neurons and synapses [3]. Clinically, AD is slowly progressive [4], usually beginning after the age of 65 years, and the risk increases with age, affecting $0.6 \%$ of the world's population for ages $65-69$ 
years, but up to $22.2 \%$ of the population over 90 years of age [5]. The number of sufferers worldwide is estimated as over 20 million [6] with more than 5 million affected in the United States.

$\mathrm{AD}$ is clinically subdivided into early $(<65$ years) and late $(\geqslant 65$ years) onset forms. About $10 \%$ of AD cases are familial with an autosomal dominant inheritance and these cases are often the early onset form [7]. Mutations in three genes, amyloid precursor protein $(A P P)$ on chromosome 21, presenilin 1 (PS1) on chromosome 14, and presenilin 2 (PS2) on chromosome 1 are estimated to account for about $50 \%$ of earlyonset AD [8-10]. However, the majority of cases (9095\%) are late-onset AD (LOAD) that can show familial clustering without a clear Mendelian mode of inheritance [11]. Apolipoprotein E (APOE) on chromosome $19 \mathrm{q} 13$ has been confirmed by multiple independent studies [12] as a risk factor for LOAD, and is associated with lowering the age of onset [1]. However, APOE explains only $20-29 \%$ of the risk [13], and it is neither essential nor sufficient to cause AD [1416]. The etiology of LOAD is complex with the possible involvement of several genes and/or environmental factors [17].

Efforts to identify additional LOAD loci have largely taken two main approaches: genome-wide linkage scans [1,18-21] and association studies of polymorphisms in candidate genes (for review see [22]). These studies indicate the existence of additional AD susceptibility genes on several chromosomes. In our genome-wide linkage scan of the National Institute of Mental Health Alzheimer's Disease Genetics Initiative (NIMH-ADGI) cohort of affected siblings, we identified five CRIs (9q22, 6q27, 14q22, 11q25, and 3p26) with suggestive linkage and one CRI on $19 \mathrm{q} 23$ that met criteria for 'significant' evidence of linkage defined by multipoint LOD scores (MLS) $\geqslant 2.0$ [1]. Other linkage studies, though considerable overlap between samples from NIMH-ADGI sets [14], have identified overlapping regions or regions that are within a modest distance of three of these CRI on $19 q 23,9 q 22$, and $11 q 25$ [15-17]. The 14q23 region was identified by an independent scan that used only Caribbean Hispanic samples [23], and serves as a separate replicate.

We followed up the CRI signal on chromosome 9q22 by genotyping additional simple tandem repeats (STRs) and found the region remained significant with an increase in the peak MLS from 2.9 to 3.8 at $95 \mathrm{cM}$ and narrowing of the CRI to $11 \mathrm{cM}(92-103 \mathrm{cM})$, thus supporting the region as potentially harboring LOAD genes [2]. In the present study, with the aim of confirm- ing our previous whole-genome scan findings, we have conducted a follow-up study with denser STR markers spanning the four remaining CRIs (3p26, 6q27, 11q25, and $14 q 22$ ). Based on the Gene Ontology (GO) terms that are annotated and enriched among the systematic meta-analyzed genes, confirmed by at least three case-control samples, and cataloged in the "AlzGene database" as potential Alzheimer disease susceptibility genes, we developed bioinformatics tools that extract potential AD candidate genes in these CRIs from genomic databases.

\section{Materials and methods}

\subsection{Study population: NIMH AD genetic initiative families}

The study subjects were collected as part of the NIMH Genetics Initiative following a standardized protocol utilizing the NINCDS-ADRDA criteria for diagnosis of definite, probable, and possible AD [24, 25]. A total of 468 families were ascertained. The primary structures of these families were affected sibpairs [1], and the ethnic make-up was primarily Caucasian $(95 \%)$. In 437 of these families, the mean age of onset (MAO) of affected family members was above 50 $($ mean $=72.4$, range $=50-97)$ (Those with MAO $\leqslant 50$ were believed to be enriched for the APP, PS1, and PS2 mutations, and were therefore dropped from the current analyses). In addition to the total set (TS, $n=437$ families), the linkage and mapping results presented here are also from a late age at onset subset with a MAO $\geqslant 65$ (LOAD families) identified in 320 families and a subset of families identified as early-mixed (EM) with MAO between ages 51 and $65(n=117)$, both with similar primary structure and ethnic make-up as the total set of families. Blood was collected and sent to the NIMH repository at Rutgers University where genomic DNA was extracted from lymphocyte cell lines.

\subsection{STR genotyping}

STRs flanking the $6 \mathrm{q} 27,14 \mathrm{q} 22,11 \mathrm{q} 25,3 \mathrm{p} 26$ peaks were chosen from the genomic database (www.gdb.org) and deCODE Genetics (www.nature.com/ng/journal/ v31/n3/ extref/ng917-S13.xls). The genetic locations of the STRs were based on sex average distances in the Rutgers combined linkage-physical map, Build 36.1 (compgen.rutgers.edu/mapomat). A total of 24 STRs were genotyped in an attempt to decrease the inter- 
Table 1

Markers used in the study, and their positions on the Rutgers combined linkage- physical map of each chromosome

\begin{tabular}{|c|c|c|c|c|c|c|c|c|c|c|c|}
\hline \multicolumn{3}{|c|}{ Chr. 6: Old CRI = 140-192 cM } & \multicolumn{3}{|c|}{ Chr. 14: Old CRI $=40-80 \mathrm{cM}$} & \multicolumn{3}{|c|}{ Chr. 11: Old CRI = 116-161 cM } & \multicolumn{3}{|c|}{ Chr. 3: Old CRI $=0-44 \mathrm{cM}$} \\
\hline $\begin{array}{l}\text { Position } \\
\text { cM }\end{array}$ & $\begin{array}{l}\text { Original } \\
\text { CIDR locus }\end{array}$ & $\begin{array}{l}\text { Follow-up } \\
\text { locus }\end{array}$ & $\begin{array}{c}\text { Position } \\
\text { cM }\end{array}$ & $\begin{array}{l}\text { Original } \\
\text { CIDR }\end{array}$ & Follow-up & $\begin{array}{c}\text { Position } \\
\text { cM }\end{array}$ & $\begin{array}{l}\text { Original } \\
\text { CIDR }\end{array}$ & Follow-up & $\begin{array}{c}\text { Position } \\
\mathrm{cM}\end{array}$ & $\begin{array}{l}\text { Original } \\
\text { CIDR }\end{array}$ & Follow-up \\
\hline 140.2 & D6S1009 & & 37.4 & D14S306 & & 115.8 & D11S1391 & & 1.9 & D3S2387 & \\
\hline 148.3 & & D6S1003 & 48 & D14S587 & & 119.8 & & D11S965 & 6.0 & & D3S3630 \\
\hline 150 & GATA184A08 & & 50.5 & & D14S276 & 122.6 & & D11S1885 & 13.2 & & D3S 1560 \\
\hline 153 & & D6S1637 & 56.6 & D14S592 & & 126.9 & D11S1998 & & 19.9 & D3S1304 & \\
\hline 156.1 & & D6S1687 & 59.3 & & D14S63 & 131.4 & & D11S4089 & 24.1 & D3S4545 & \\
\hline 158.2 & & D6S494 & 63.7 & D14S588 & & 137.2 & D11S4464 & & 31.6 & DD3S1259 & \\
\hline 160 & & D6S2420 & 68.7 & & D14S77 & 145.1 & D11S912 & & 36.9 & & D3S1286 \\
\hline 162.9 & D6S2436 & & 69.8 & & D14S71 & 152.8 & & D11S4131 & 43.8 & D3S3038 & \\
\hline 165.8 & & D6S442 & 70.3 & & D14S43 & 160.7 & D11S968 & & & & \\
\hline 169.4 & & D6S437 & 72.4 & & D14S61 & & & & & & \\
\hline 178.5 & D6S1277 & & 72.7 & D14S53 & & & & & & & \\
\hline 181.4 & & D6S1719 & 79.4 & D14S606 & & & & & & & \\
\hline 183 & & D6S264 & 84.5 & & D14S48 & & & & & & \\
\hline 188.5 & & D6S503 & & & & & & & & & \\
\hline 191.6 & D6S1027 & & & & & & & & & & \\
\hline
\end{tabular}

marker genomic distance in these four peak regions in these LOAD families, which was $9 \mathrm{cM}$ in the original scan. The STRs genotyped for the original and follow-up mapping are listed in Table 1.

All STR genotyping for follow-up mapping on chromosomes $3 p, 6 q$ and $11 \mathrm{q}$ were performed with the Beckman/Coulter CEQ 8000 capillary electrophoresis platform with Well RED dyes (Beckman/Coulter, Fullerton, CA) as described previously [2]. The ratio of each of the flanking STRs in the two pooled products that were run on the CEQ platform was determined by the dye selection criteria [2]. The ratio of the six flanking markers on 6q27 (D6S1687, D6S2420, D6S1719, D6S494, D6S1637, D6S442) was 1.3:3:1.6:3:3.5:1.3, respectively while the ratio of flanking STRs on $3 \mathrm{p} 26$ and 11q25 (D3S3630, D3S1560, D3S1286, D11S965, D11S4089, D11S4131, D11S1885) were pooled as 3:2.75:1.25:2.75:3:1.8:1.25, respectively. The seven flanking STRs on chromosome $14 \mathrm{q}$ and the four remaining markers on chromosome 6q27 were genotyped by acrylamide electrophoresis using autoradiography as described previously [26].

\subsection{Linkage analysis}

The statistical analyses have been detailed previously [2]. In brief, model-free linkage analysis was performed using the program Genehunter Plus with extensions to calculate the Kong and Cox statistic [27,28]. Maximum likelihood estimates of allele frequencies were calculated with the SAGE [29] program FREQ taking into account the family relationships. Replicates were performed on selected samples and any Mendelian errors were detected with the SAGE program MARK-
ERINFO, as well as detected implicitly by the analytical programs used here.

\subsection{Bioinformatics approach for candidate gene selection in CRIs}

Once a linkage peak has been identified, hundreds of genes under the peak can be accessed using the UCSC genome browser (http://genome.ucsc.edu). But the lists are too large to conduct expensive molecular lab work. We developed a bioinformatics approach using a Python (http://www.python.org) script to assist in the efficient automatic extraction of candidate genes in regions of linkage (the codes are available upon request). Specific procedures for AD are: 1 . The region to be analyzed needs to be defined. The input regions are usually defined as the 1 LOD drop of the linkage peak whose physical location is defined by the closest markers to the ends of the regions. 2. A list of disease specific keywords generated from 24 meta-analyzed and confirmed AD genes (http://www.alzgene.org; accessed on July 2, 2007 ) is provided to the program. These lists are function and process key terms deposited in the Gene Ontology (GO) databases (http://www.geneontology.org; accessed on July 2, 2007) for this disease. GO is developed to capture the activities at cellular and molecular level. For AD, these terms are, in general, related to neurological function, inflammation, oxidative damage, cholesterol/lipoprotein function and atherosclerosis/vascular pathways [30]. As of 2006, there are about $18,455 \mathrm{GO}$ terms assigned to proteins to illustrate what they do, where they function, and what processes they are involved in. The AlzGene (http://www.alzgene.org) with in the Alzforum (http://www.alzforum.org) cat- 
alogue, "AlzGene database", is a systematic, metaanalyses of potential Alzheimer disease susceptibility genes in at least three case-control samples [22]. This gene database is expected to provide a powerful tool for deciphering the genetics of Alzheimer disease, and serve as a potential model for tracking the most viable candidate genes.

Based on the GO vocabulary terms of the 24 most significant genes identified by Algene, we developed a bioinformatics approach to identify candidate genes in our QTL regions linked to AD. Briefly, we articulate that these GO terms for these 24 candidate liability genes (Table 2) can serve as a model in discovering new AD genes in each of our linkage peak regions. For each gene, we downloaded two categories of GO terms, function and process, from GO databases and interrogated the linkage regions of interest with theses GO terms for possible candidate AD genes. Genes enriched with the specified AD related GO terms are then downloaded directly from the human genome draft Build 36.1 database (http://genome.ucsc.edu) assembly.

\section{Results}

\subsection{CRI located at $6 q 27$}

The chromosome 6q27 interval (140-192 cM) had a peak MLS score of 2.2. We have genotyped an additional ten markers and decreased the MID in this region from $10.9 \mathrm{cM}$ to $3.8 \mathrm{cM}$. Additionally, the interval of support in the follow-up scan narrows to $148-188 \mathrm{cM}$ (Table 1). Graph of the MLS scores from the total dataset showed the extra marker information split the peak: one signal located between 140 and $165 \mathrm{cM}$ in the LOAD group with a peak MLS of 0.95 at $153 \mathrm{cM}$ and a second CRI located between 170 and $192 \mathrm{cM}$ in the EM group with a peak MLS of 1.48 at $183 \mathrm{cM}$ (Fig. 1a).

\subsection{CRI located at $14 q 22$}

The CRI we identified at $14 q 22(37-80 \mathrm{cM})$ in the original scan had the highest MLS in the EM subset of families (MLS = 2.2). This evidence is probably due in large part to the presence of the PSEN1 gene located within this region at $68.7 \mathrm{cM}$. We have genotyped an additional 7 markers in this region, reducing the MID from 6.7 to $3.0 \mathrm{cM}$, and increasing the IC from 0.30 0.54 to $0.44-0.65$. Additionally, the interval of support in the follow-up scan narrows to $50-85 \mathrm{cM}$ (Table 1).
The CRI is confirmed in the EM group between 35 and $75 \mathrm{cM}$ with an increase in the peak MLS score from 2.2 to 2.5 at $48 \mathrm{cM}$ (Fig. 1b). This places the peak $\sim 20 \mathrm{cM}$ proximal to PSEN1, which suggests the location of a possible second susceptibility gene in the EM group.

\subsection{CRI located at $11 q 27$}

Four additional microsatellites were genotyped in the CRI located at 11q25 $(116-161 \mathrm{cM})$, resulting in a decrease in the MID of this region to $5.0 \mathrm{cM}$ from an MID of $9.0 \mathrm{cM}$, and an increase of IC from $0.39-0.52$ to 0.45-0.62. Additionally, the interval of support in the follow-up scan narrows to $120-153 \mathrm{cM}$ (Table 1). The peak MLS remained unchanged from the original scan $(2.0$ at $158 \mathrm{cM})$ for the total set and there was narrowing of the signal to a region between 130 and $164 \mathrm{cM}$ (Fig. 1c).

\subsection{CRI located at $3 p 26$}

The CRI located at 3p26 had an MLS of 2.0 in the original scan in the EM and CM sets. We have genotyped three additional markers in this region, that result an increase in IC from $0.32-0.52$ to $0.43-0.65$ and a decrease in the MID from 8.8 to $5.3 \mathrm{cM}$. The peak MLS for the EM set and the combined set decreased to 1.45 and there was no narrowing of the region. Since we wish to maintain our stringent criteria of an MLS $\geqslant 2.0$ for confirmation of a CRI and because there is no supporting evidence of the 3 p26 region linked to $\mathrm{AD}$ in other genomic scans, this signal is most likely a false positive, therefore we have omitted this region from any further investigations.

\subsection{Candidate gene selection}

Results of possible candidate genes in these CRIs and their locations from the interrogation of the database with the GO terms are presented on Table 3. Approximately 159 position-based candidate genes and nearly 53,313 HapMap Caucasian SNPs (http://genome.ucsc.edu) were found at the 6q27 CRI (140-192 cM peak). Our bioinformatics procedure reduced the candidate gene lists to 56 based on function and 48 based on process, with 24 that were overlapping genes. At the interval $(35-75 \mathrm{cM})$ of the $14 \mathrm{q} 22$ peak, about 198 genes and nearly 58,438 HapMap Caucasian SNPs were found. The interrogation of the database using GO terms reduced the candidate genes to 107 based on function and 69 based on process, with 46 that 


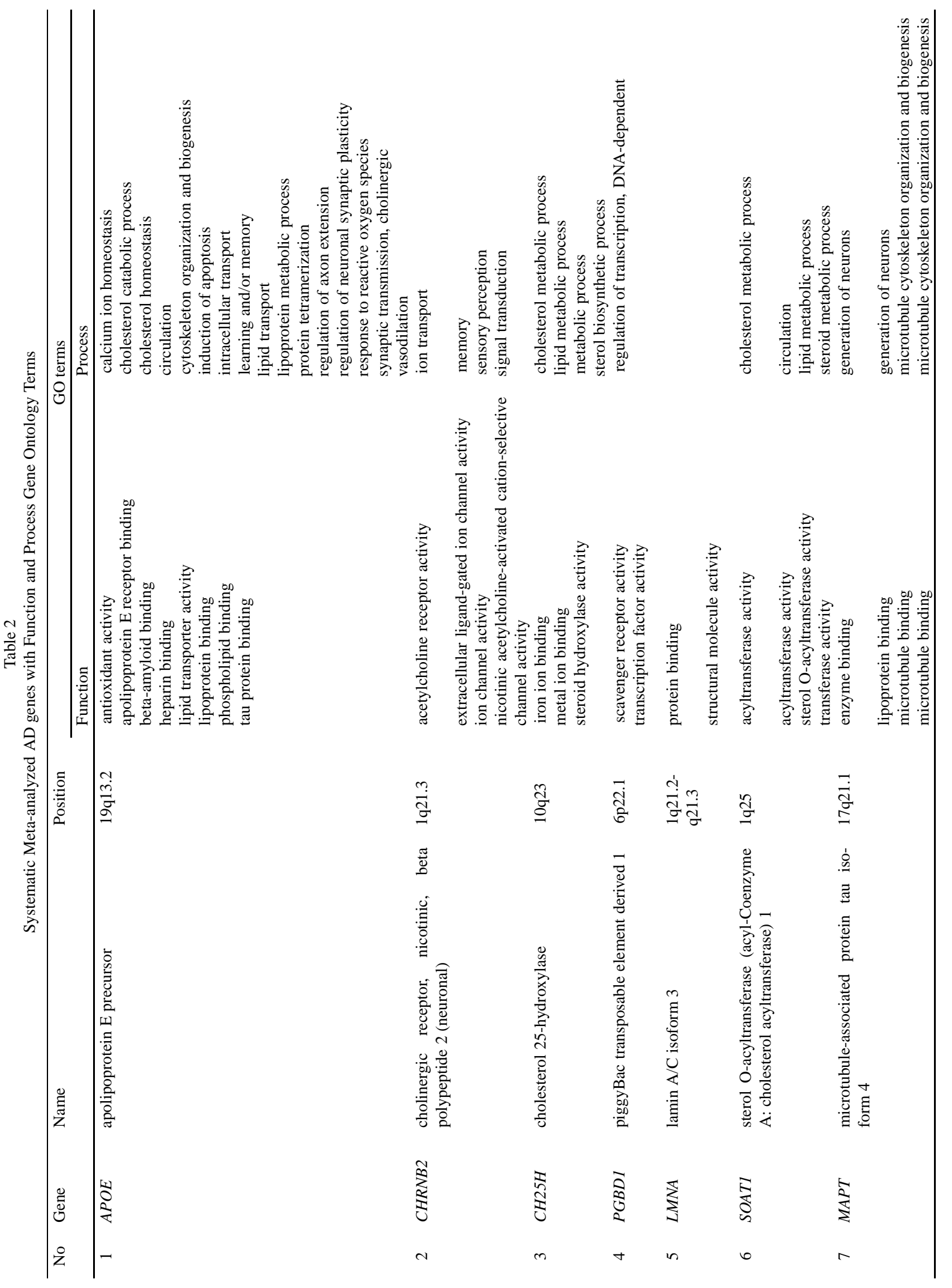




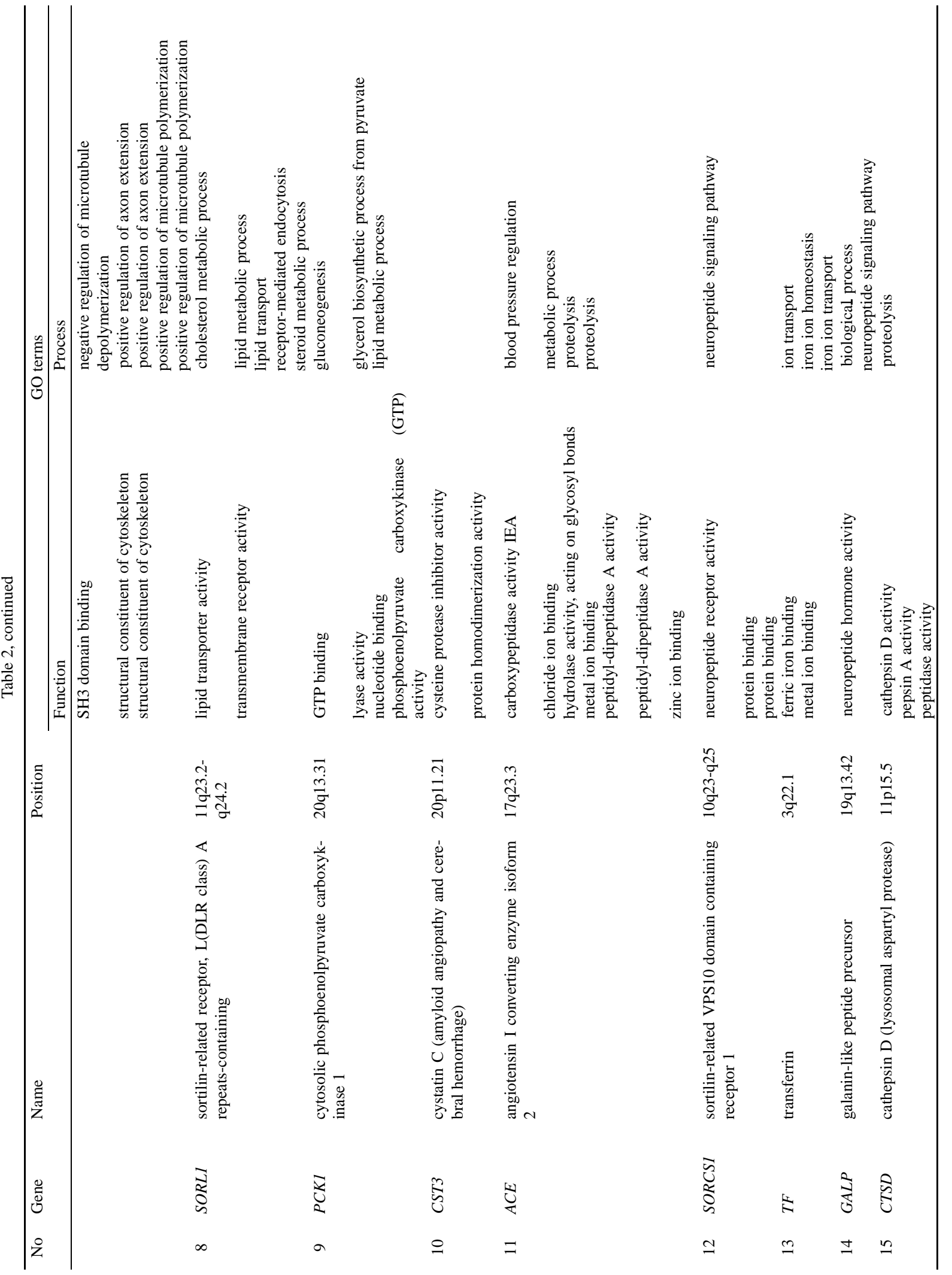



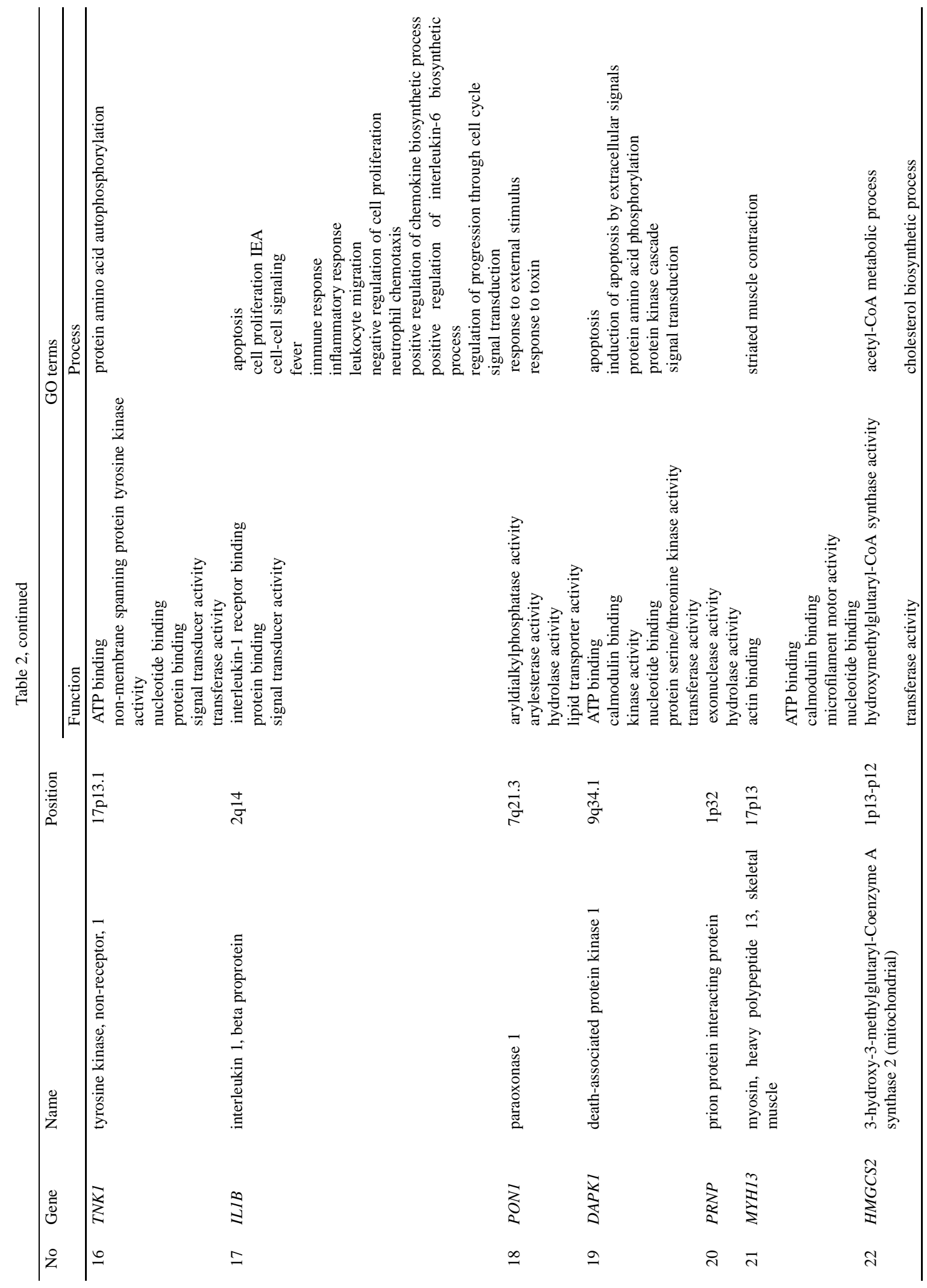


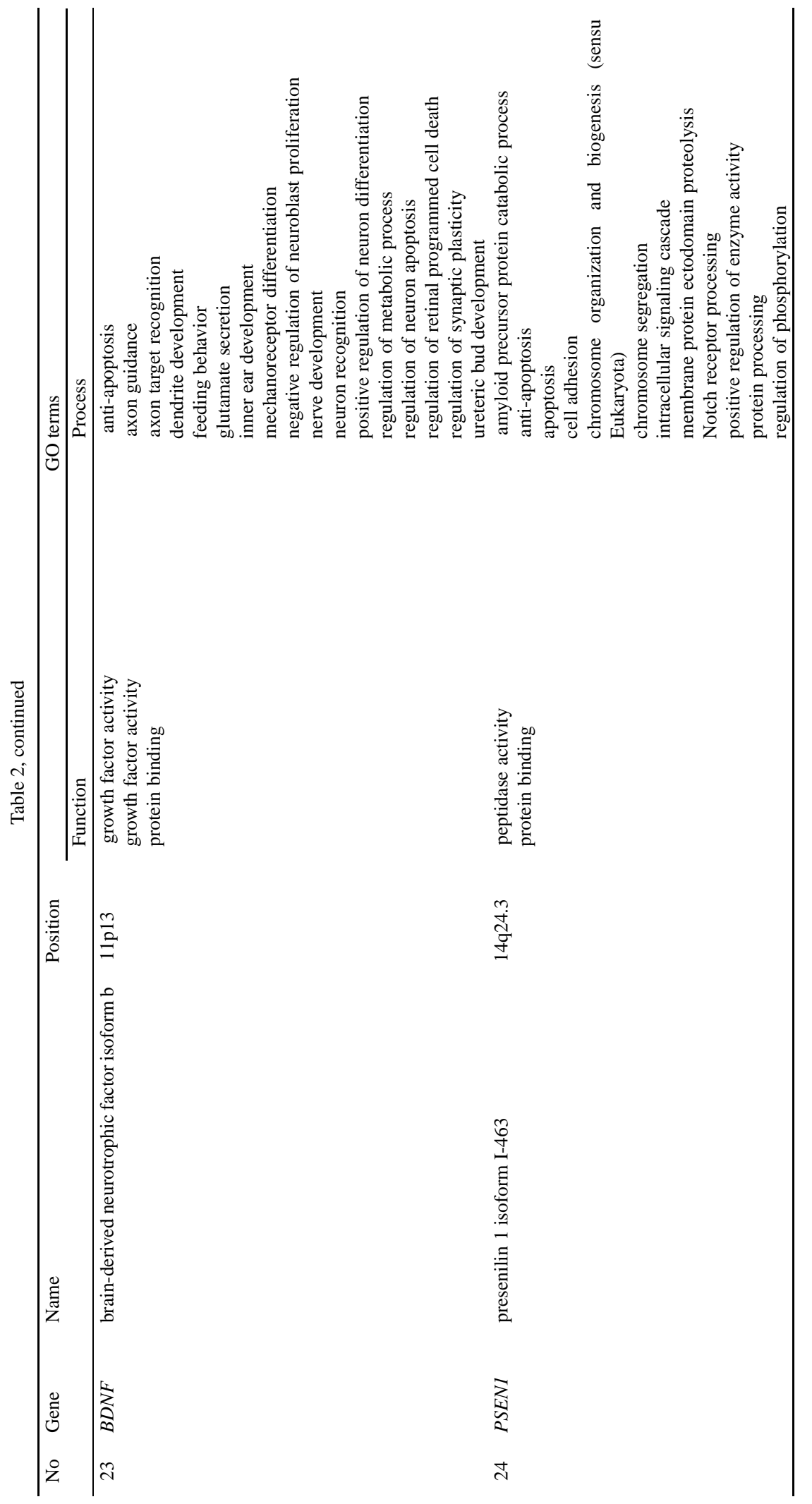


a. Follow-up mapping of the $6 q 27$ candidate region

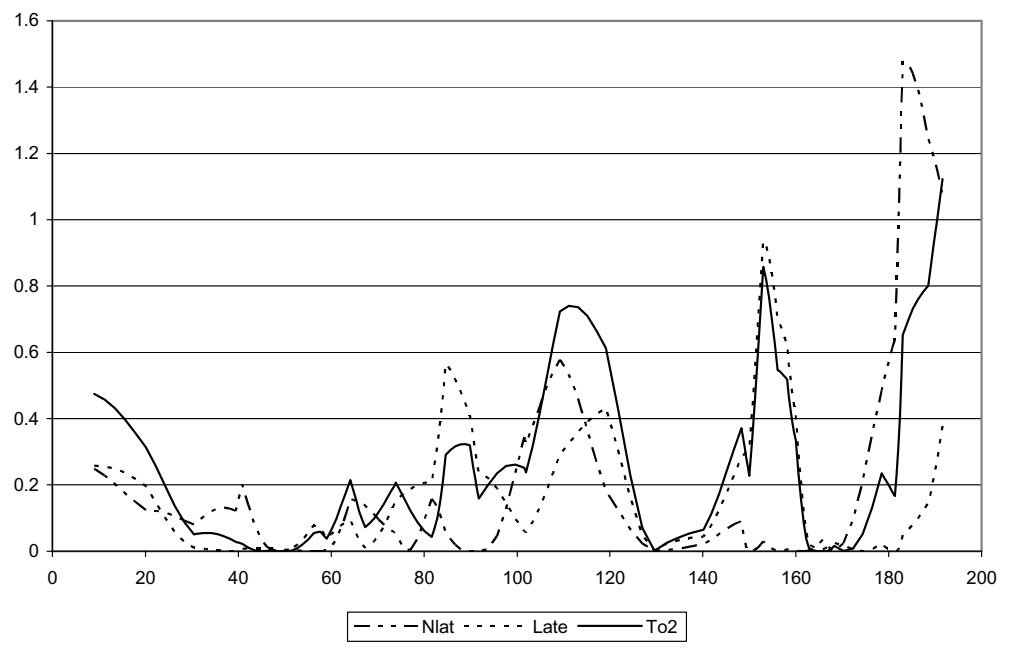

b. Follow-up mapping of the $14 \mathrm{q} 22$ candidate region
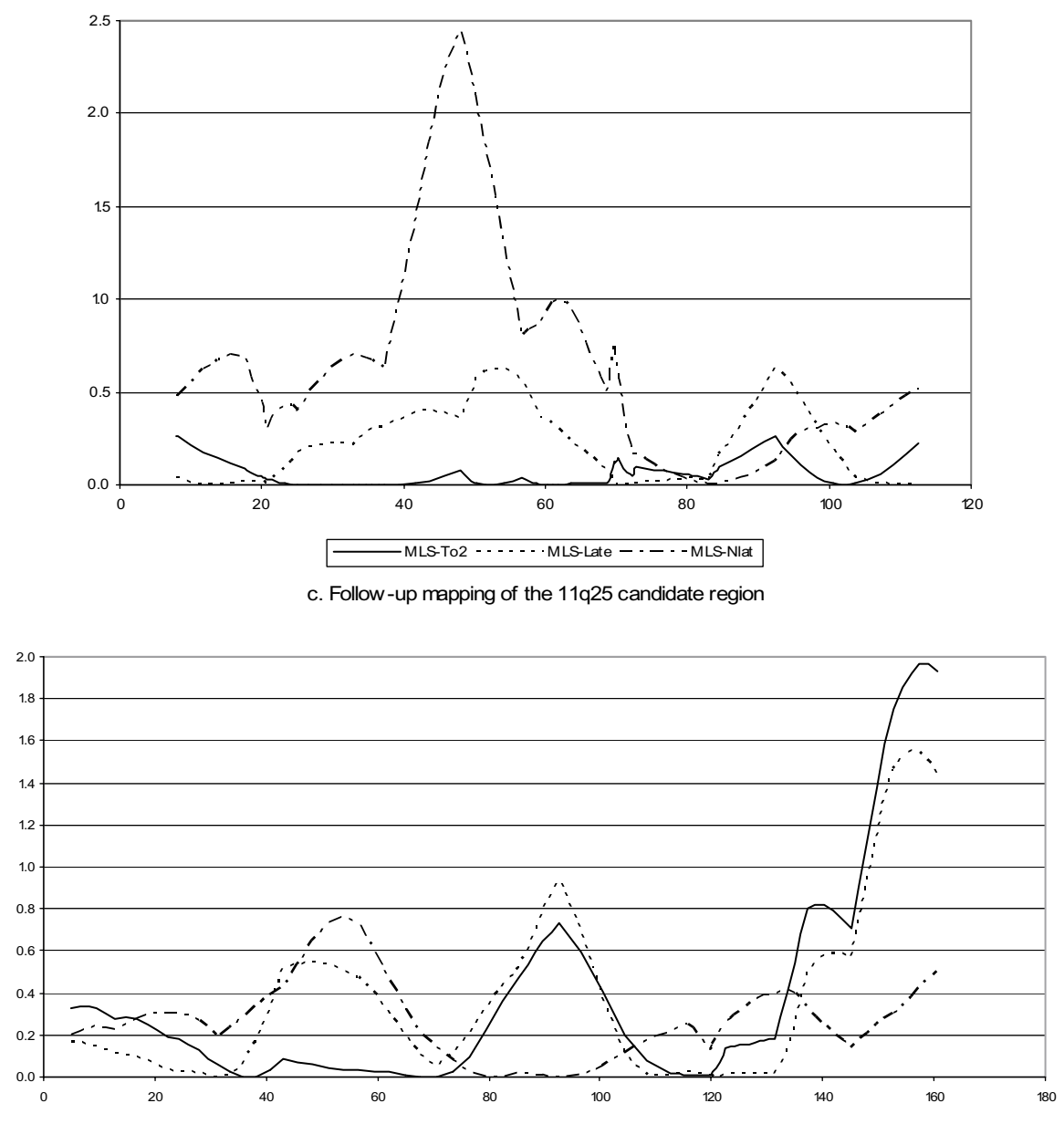

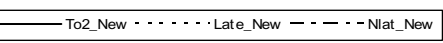

Fig. 1. MLS data of follow-up scan with an additional dense grid of markers for the CRIs on chromosome 6 (1a), 14 (1b), 11 (1c). 
Table 3

Lists of total, functional, process genes in $6 \mathrm{q}, 14 \mathrm{q}$ and $11 \mathrm{q}$ CRI

\begin{tabular}{|c|c|c|c|c|c|c|c|c|}
\hline \multicolumn{3}{|c|}{ chr 6 (140-192cM) } & \multicolumn{3}{|c|}{ chr $14(35-75 \mathrm{cM})$} & \multicolumn{3}{|c|}{ chr $11(130-164 \mathrm{cM})$} \\
\hline Total & Function & Process & Total & Function & Process & Total & Function & Process \\
\hline 159 genes & 56 genes & 48 genes & 198 genes & 107 genes & 69 genes & 83 genes & 12 genes & 26 genes \\
\hline ACAT2 & ACAT2 & AKAP12 & ABCD4 & $\mathrm{ABCD} 4$ & ADAM20 & AB045830 & ARHGEF12 & ESAM \\
\hline AGPAT4 & AGPAT4 & ARID1B & ACTN1 & ACOT1 & ADAM21 & ACAD8 & ESAM & GRIK4 \\
\hline AIG1 & AKAP12 & BCLAF1 & ACTR10 & ACOT2 & AKAP5 & ACRV1 & GRIK4 & NRGN \\
\hline AKAP12 & ARID1B & C6orf103 & ACYP1 & ACOT4 & ARF6 & ADAMTS15 & HSPA8 & OR10G4 \\
\hline ARID1B & BCLAF1 & C6orf123 & ADAM20 & ACTN1 & ATP5S & ADAMTS8 & NRGN & OR10G7 \\
\hline BCLAF1 & CITED2 & C6orf54 & ADAM21 & ACTR10 & ATP6V1D & APLP2 & PKNOX2 & OR10G8 \\
\hline BRP44L & CLDN20 & CCR6 & ADCK1 & ACYP1 & BATF & ARHGEF12 & POU2F3 & OR10G9 \\
\hline C6orf103 & CNKSR3 & ESR1 & AF161445 & ADAM20 & BMP4 & ASAM & SC5DL & OR4D5 \\
\hline C6orf115 & EPM2A & FBXO5 & AF336880 & ADAM21 & CDKL1 & AY358331 & SIAE & OR6M1 \\
\hline C6orf118 & ESR1 & GPR126 & AF390028 & AKAP5 & CDKN3 & B3GAT1 & SORL1* & OR6X1 \\
\hline C6orf120 & FBXO30 & GPR31 & AF390029 & ARF6 & CGRRF1 & BARX2 & TRIM29 & OR8B12 \\
\hline C6orf122 & FBXO5 & GRM1 & AF435011 & ARG2 & CHURC1 & ВC030580 & ZNF202 & OR8B2 \\
\hline C6orf123 & HIVEP2 & GTF2H5 & AHSA1 & ARID4A & CHX10 & BRCC2 & & OR8B3 \\
\hline C6orf208 & KATNA1 & HIVEP2 & AKAP5 & ATP6V1D & CNIH & $\mathrm{CDON}$ & & OR8B4 \\
\hline C6orf211 & KIF25 & IFNGR1 & AL833179 & BATF & DLG7 & CHEK1 & & OR8B8 \\
\hline C6orf35 & LATS1 & IGF2R & ALDH6A1 & BMP4 & DPF3 & CR625776 & & OR8D1 \\
\hline C6orf54 & LPA & LATS1 & ALKBH & BTBD5 & ERH & CRTAM & & OR8D2 \\
\hline C6orf55 & MAP3K5 & LOC653483 & ARF6 & C14orf4 & ESR2 & CSE-C & & OR8D4 \\
\hline C6orf59 & MAP3K7IP2 & LPA & ARG2 & CDKL1 & ESRRB & DCPS & & OR8G2 \\
\hline C6orf70 & MAP7 & LPAL2 & ARID4A & CDKN3 & FOS & DDX25 & & OR8G5 \\
\hline C6orf71 & MLLT4 & MAP3K4 & ATP6V1D & CGRRF1 & FOXA1 & ESAM & & PKNOX2 \\
\hline C6orf72 & MTHFD1L & MАР3К5 & AY451390 & CHURC1 & GNG2 & FEZ1 & & ROBO3 \\
\hline C6orf96 & PARK2 & MAS1 & BATF & CHX10 & GPR135 & FLI1 & & SCN3B \\
\hline C6orf97 & PCMT1 & MLLT4 & BC006221 & CTAGE5 & HIF1A & GRIK4 & & SORL1* \\
\hline CCDC28A & PDE10A & NMBR & ВC011548 & DAAM1 & KCNH5 & HSPA8 & & SPA17 \\
\hline CCR6 & PDE7B & OLIG3 & ВС090945 & DDHD1 & LTBP2 & ITM1 & & ZNF202 \\
\hline CITED2 & PERP & OPRM1 & BMP4 & DLG7 & MAP3K9 & JAM3 & & \\
\hline CLDN20 & PEX3 & PDE10A & BRMS1L & DLST & MAP4K5 & KCNJ1 & & \\
\hline CNKSR3 & PHACTR2 & PDE7B & BTBD5 & DPF3 & MAX & KCNJ5 & & \\
\hline DACT2 & PHF10 & PERP & C14orf101 & ENTPD5 & MNAT1 & KIRREL3 & & \\
\hline DEADC1 & PLAGL1 & PHF10 & C14orf106 & ESR2 & NEK9 & LOH11CR2A & & \\
\hline DLL1 & PLG & PLAGL1 & C14orf111 & ESRRB & NID2 & LRRC35 & & \\
\hline DYNLT1 & PPIL4 & PLG & C14orf140 & EXDL2 & NKX2-8 & NFRKB & & \\
\hline EPM2A & RAB32 & RAB32 & C14orf162 & FANCM & NPC2 & NRGN & & \\
\hline ESR1 & RAET1E & RPS6KA2 & C14orf166 & FNTB & NRXN3 & OPCML & & \\
\hline FAM120B & RAET1G & SHPRH & C14orf29 & FOS & OTX2 & OR10G4 & & \\
\hline FAM54A & RBM16 & SLC22A1 & C14orf31 & FOXA1 & PAPLN & OR10G7 & & \\
\hline FBXO30 & RGS17 & SLC22A2 & C14orf32 & GCH1 & PAX9 & OR10G8 & & \\
\hline FBXO5 & RNASET2 & SLC22A3 & C14orf4 & GMFB & PGF & OR10G9 & & \\
\hline FGFR1OP & SHPRH & SNX9 & CDKN3 & GNG2 & PLEK2 & OR10S1 & & \\
\hline FLJ27255 & SLC22A1 & TAGAP & CGRRF1 & GNPNAT1 & PLEKHC1 & OR4D5 & & \\
\hline FLJ37060 & SLC22A2 & THBS2 & CHURC1 & GSTZ1 & PNN & OR6M1 & & \\
\hline FLJ39824 & SNX9 & TIAM2 & CHX10 & HIF1A & PPP2R5E & OR6T1 & & \\
\hline FLJ44955 & SOD2 & TNFAIP3 & CLEC14A & HSPA2 & PRKCH & OR6X1 & & \\
\hline FNDC1 & STX11 & TULP4 & $\mathrm{CNIH}$ & KCNH5 & PSEN1* & OR8A1 & & \\
\hline FRMD1 & SYNE1 & UNC93A & COQ6 & MAP3K9 & PTGDR & OR8B12 & & \\
\hline FUCA2 & SYNJ2 & VIP & CTAGE5 & MAP4K5 & PTGER2 & OR8B2 & & \\
\hline GPR126 & SYTL3 & ZBTB2 & DAAM1 & MAX & RAB15 & OR8B3 & & \\
\hline GPR178 & TCP1 & & DACT1 & MLH3 & RGS6 & OR8B4 & & \\
\hline GPR31 & THBS2 & & DDHD1 & MNAT1 & RPS6KL1 & OR8B8 & & \\
\hline GRM1 & TNFAIP3 & & DHRS7 & MPP5 & RTN1 & OR8D1 & & \\
\hline GTF2H5 & TULP4 & & DLG7 & MTHFD1 & SAV1 & OR8D2 & & \\
\hline HEBP2 & UST & & DLST & NEK9 & SIX1 & OR8D4 & & \\
\hline HECA & VIL2 & & EIF2B2 & NGB & SIX4 & OR8G2 & & \\
\hline HIVEP2 & ZBTB2 & & EIF2S1 & NIN & SIX6 & OR8G5 & & \\
\hline IFNGR1 & ZDHHC14 & & ENTPD5 & NKX2-8 & SLC10A1 & PANX3 & & \\
\hline IGF2R & & & ERH & NRXN3 & SLC8A3 & PATE & & \\
\hline
\end{tabular}


Table 3, continued

\begin{tabular}{|c|c|c|c|c|c|c|c|c|}
\hline \multicolumn{3}{|c|}{ chr 6 (140-192cM) } & \multicolumn{3}{|c|}{ chr $14(35-75 \mathrm{cM})$} & \multicolumn{3}{|c|}{ chr $11(130-164 \mathrm{cM})$} \\
\hline $\begin{array}{l}\text { Total } \\
159 \text { genes }\end{array}$ & $\begin{array}{l}\text { Function } \\
56 \text { genes }\end{array}$ & $\begin{array}{l}\text { Process } \\
48 \text { genes }\end{array}$ & $\begin{array}{l}\text { Total } \\
198 \text { genes }\end{array}$ & $\begin{array}{l}\text { Function } \\
107 \text { genes }\end{array}$ & $\begin{array}{l}\text { Process } \\
69 \text { genes }\end{array}$ & $\begin{array}{l}\text { Total } \\
83 \text { genes }\end{array}$ & $\begin{array}{l}\text { Function } \\
12 \text { genes }\end{array}$ & $\begin{array}{l}\text { Process } \\
26 \text { genes }\end{array}$ \\
\hline IL20RA & & & ERO1L & NUMB & SNAPC1 & PMP22CD & & \\
\hline IL22RA2 & & & ESR2 & OTX2 & SOCS4 & POU2F3 & & \\
\hline KATNA1 & & & FBXO33 & PAPLN & SPG3A & PRDM10 & & \\
\hline KIAA1244 & & & FBXO34 & PELI2 & SSTR1 & PUS3 & & \\
\hline KIF25 & & & FKBP3 & PGF & TGFB3 & RICS & & \\
\hline LATS1 & & & FNTB & PLEKHC1 & TITF1 & ROBO3 & & \\
\hline LOC202459 & & & FOS & PNMA1 & TXNDC & ROBO4 & & \\
\hline LOC401280 & & & FOXA1 & POLE2 & VTI1B & RPUSD4 & & \\
\hline LOC401286 & & & FUT8 & PPM1A & WDHD1 & SC5DL & & \\
\hline LOC441177 & & & GARNL1 & PRKCH & ZBTB1 & SCN3B & & \\
\hline LOC441179 & & & GCH1 & PSEN1* & ZBTB25 & SLC37A2 & & \\
\hline LOC653483 & & & GMFB & PSMA3 & ZNF410 & SNX19 & & \\
\hline LPA & & & GNG2 & PSMC6 & & SORL1 & & \\
\hline LPAL2 & & & GNPNAT1 & PYGL & & SPA17 & & \\
\hline LRP11 & & & GPHN & RAB15 & & SPATA19 & & \\
\hline LTV1 & & & GPR135 & RAD51L1 & & SRPR & & \\
\hline MAP3K4 & & & GPX2 & RBM25 & & ST14 & & \\
\hline MAP3K5 & & & GSTZ1 & RGS6 & & ST3GAL4 & & \\
\hline MAP3K7IP2 & & & HBLD1 & RHOJ & & STS-1 & & \\
\hline MAP7 & & & HIF1A & RPS6KL1 & & TBRG1 & & \\
\hline MAS1 & & & HSPA2 & RTN1 & & TECTA & & \\
\hline MGC35308 & & & JDP2 & SAV1 & & THY28 & & \\
\hline MLLT4 & & & KCNH5 & SEC23A & & TIRAP & & \\
\hline MRPL18 & & & KIAA0317 & SFRS5 & & TMEM45B & & \\
\hline MTHFD1L & & & KIAA0586 & SGPP1 & & VSIG2 & & \\
\hline MTRF1L & & & KIAA1036 & SIP1 & & ZNF202 & & \\
\hline MYCT1 & & & KIAA1393 & SIPA1L1 & & & & \\
\hline NMBR & & & KIAA1737 & SIX1 & & & & \\
\hline NOX3 & & & KLHDC1 & SIX4 & & & & \\
\hline NUP43 & & & KLHDC2 & SIX6 & & & & \\
\hline OLIG3 & & & KTN1 & SLC8A3 & & & & \\
\hline OPRM1 & & & LGALS3 & SNW1 & & & & \\
\hline PACRG & & & LRFN5 & SPG3A & & & & \\
\hline PARK2 & & & LTBP2 & SPTB & & & & \\
\hline PBOV1 & & & MAMDC1 & SPTLC2 & & & & \\
\hline PCMT1 & & & MAP3K9 & STYX & & & & \\
\hline PDE10A & & & MAP4K5 & SYNE2 & & & & \\
\hline PDE7B & & & MAX & SYNJ2BP & & & & \\
\hline PERP & & & MBIP & TGFB3 & & & & \\
\hline PEX3 & & & MED6 & TIMM9 & & & & \\
\hline PEX7 & & & MGAT2 & TITF1 & & & & \\
\hline PHACTR2 & & & MIA2 & TRIM9 & & & & \\
\hline PHF10 & & & MIPOL1 & TTLL5 & & & & \\
\hline PIP3-E & & & MLH3 & ZADH1 & & & & \\
\hline PLAGL1 & & & MNAT1 & ZBTB1 & & & & \\
\hline PLG & & & MPP5 & ZBTB25 & & & & \\
\hline PNLDC1 & & & MTHFD1 & ZFP36L1 & & & & \\
\hline PPIL4 & & & NEK9 & ZFYVE1 & & & & \\
\hline PPP1R14C & & & NGB & ZFYVE26 & & & & \\
\hline QKI & & & NID2 & ZNF410 & & & & \\
\hline RAB32 & & & NIN & & & & & \\
\hline RAET1E & & & NKX2-8 & & & & & \\
\hline RAET1G & & & NPC2 & & & & & \\
\hline RAET1L & & & NRXN3 & & & & & \\
\hline RBM16 & & & NUMB & & & & & \\
\hline REPS1 & & & OTX2 & & & & & \\
\hline RGS17 & & & PAPLN & & & & & \\
\hline RNASET2 & & & PAX9 & & & & & \\
\hline RPS6KA2 & & & PCNX & & & & & \\
\hline
\end{tabular}




\begin{tabular}{|c|c|c|c|c|c|c|c|c|}
\hline \multicolumn{3}{|c|}{$\operatorname{chr} 6(140-192 \mathrm{cM})$} & \multicolumn{3}{|c|}{ chr $14(35-75 \mathrm{cM})$} & \multicolumn{3}{|c|}{ chr $11(130-164 \mathrm{cM})$} \\
\hline $\begin{array}{l}\text { Total } \\
159 \text { genes }\end{array}$ & $\begin{array}{l}\text { Function } \\
56 \text { genes }\end{array}$ & $\begin{array}{l}\text { Process } \\
48 \text { genes }\end{array}$ & $\begin{array}{l}\text { Total } \\
198 \text { genes }\end{array}$ & $\begin{array}{l}\text { Function } \\
107 \text { genes }\end{array}$ & $\begin{array}{l}\text { Process } \\
69 \text { genes }\end{array}$ & $\begin{array}{l}\text { Total } \\
83 \text { genes }\end{array}$ & $\begin{array}{l}\text { Function } \\
12 \text { genes }\end{array}$ & $\begin{array}{l}\text { Process } \\
26 \text { genes }\end{array}$ \\
\hline RSHL2 & & & PELI2 & & & & & \\
\hline SASH1 & & & PGF & & & & & \\
\hline SERAC1 & & & PIGH & & & & & \\
\hline SF3B5 & & & PLEK2 & & & & & \\
\hline SFT2D1 & & & PLEKHC1 & & & & & \\
\hline SHPRH & & & PLEKHG3 & & & & & \\
\hline SLC22A1 & & & PLEKHH1 & & & & & \\
\hline SLC22A2 & & & PNMA1 & & & & & \\
\hline SLC22A3 & & & PNN & & & & & \\
\hline SLC35D3 & & & POLE2 & & & & & \\
\hline SMOC2 & & & POMT2 & & & & & \\
\hline SNX9 & & & PPIL5 & & & & & \\
\hline SOD2 & & & PPM1A & & & & & \\
\hline STX11 & & & PPP2R5E & & & & & \\
\hline STXBP5 & & & PRKCH & & & & & \\
\hline SUMO4 & & & PRPF39 & & & & & \\
\hline SYNE1 & & & PSEN1 & & & & & \\
\hline SYNJ2 & & & PSMA3 & & & & & \\
\hline SYTL3 & & & PSMC6 & & & & & \\
\hline $\mathrm{T}$ & & & PTGDR & & & & & \\
\hline TAGAP & & & PTGER2 & & & & & \\
\hline TCP1 & & & PYGL & & & & & \\
\hline TCP10 & & & RAB15 & & & & & \\
\hline TCP10L2 & & & RAD51L1 & & & & & \\
\hline TCTE3 & & & RBM25 & & & & & \\
\hline TFB1M & & & RDH11 & & & & & \\
\hline THBS2 & & & RDH12 & & & & & \\
\hline TIAM2 & & & RGS6 & & & & & \\
\hline TNFAIP3 & & & RHOJ & & & & & \\
\hline TTLL2 & & & RPL10L & & & & & \\
\hline TULP4 & & & RPL36AL & & & & & \\
\hline TXLNB & & & RPS29 & & & & & \\
\hline ULBP1 & & & RPS6KL1 & & & & & \\
\hline ULBP2 & & & RTN1 & & & & & \\
\hline ULBP3 & & & SAMD4 & & & & & \\
\hline UNC93A & & & SAV1 & & & & & \\
\hline UST & & & SDCCAG1 & & & & & \\
\hline VIL2 & & & SEC10L1 & & & & & \\
\hline VIP & & & SEC23A & & & & & \\
\hline WDR27 & & & SFRS5 & & & & & \\
\hline WTAP & & & SGPP1 & & & & & \\
\hline ZBTB2 & & & SIP1 & & & & & \\
\hline ZDHHC14 & & & SIPA1L1 & & & & & \\
\hline & & & SIX1 & & & & & \\
\hline & & & SIX4 & & & & & \\
\hline & & & SIX6 & & & & & \\
\hline & & & SKIIP & & & & & \\
\hline & & & SLC10A1 & & & & & \\
\hline & & & SLC25A21 & & & & & \\
\hline & & & SLC38A6 & & & & & \\
\hline & & & SLC39A9 & & & & & \\
\hline & & & SLC8A3 & & & & & \\
\hline & & & SNAPC1 & & & & & \\
\hline & & & SOCS4 & & & & & \\
\hline & & & SPG3A & & & & & \\
\hline & & & SPTB & & & & & \\
\hline & & & SPTLC2 & & & & & \\
\hline & & & SSTR1 & & & & & \\
\hline & & & STYX & & & & & \\
\hline
\end{tabular}




\begin{tabular}{|c|c|c|c|c|c|c|c|c|}
\hline \multicolumn{3}{|c|}{ chr 6 (140-192cM) } & \multicolumn{3}{|c|}{ chr $14(35-75 \mathrm{cM})$} & \multicolumn{3}{|c|}{ chr $11(130-164 \mathrm{cM})$} \\
\hline $\begin{array}{l}\text { Total } \\
159 \text { genes }\end{array}$ & $\begin{array}{l}\text { Function } \\
56 \text { genes }\end{array}$ & $\begin{array}{l}\text { Process } \\
48 \text { genes }\end{array}$ & $\begin{array}{l}\text { Total } \\
198 \text { genes }\end{array}$ & $\begin{array}{l}\text { Function } \\
107 \text { genes }\end{array}$ & $\begin{array}{l}\text { Process } \\
69 \text { genes }\end{array}$ & $\begin{array}{l}\text { Total } \\
83 \text { genes }\end{array}$ & $\begin{array}{l}\text { Function } \\
12 \text { genes }\end{array}$ & $\begin{array}{l}\text { Process } \\
26 \text { genes }\end{array}$ \\
\hline & & & $\begin{array}{l}\text { SYNJ2BP } \\
\text { SYT14L } \\
\text { TBPL2 } \\
\text { TGFB3 } \\
\text { THSD3 } \\
\text { TIMM9 } \\
\text { TMED8 } \\
\text { TMP21 } \\
\text { TRIM9 } \\
\text { TTC6 } \\
\text { TXNDC } \\
\text { VTI1B } \\
\text { WDHD1 } \\
\text { WDR21A } \\
\text { WDR22 } \\
\text { ZADH1 } \\
\text { ZAP128 } \\
\text { ZBTB1 } \\
\text { ZBTB25 } \\
\text { ZFP36L1 } \\
\text { ZFYVE1 } \\
\text { ZFYVE26 } \\
\text { ZNF410 }\end{array}$ & & & & & \\
\hline
\end{tabular}

Genes in bold are common to function and process GO terms, and* are genes that belong to the 24 'Alzgene database'.

overlapped. About 83 genes and nearly 8,321 HapMap Caucasian SNPs were recorded at the 11q22 QTL peak interval (116-161 cM) and our bioinformatics procedure reduced the candidate gene lists to 12 genes based on function and 26 based on process, with about 6 genes overlapping.

\section{Discussion}

Follow-up linkage analyses utilizing an additional 24 STRs with an average intermarker distance of $\sim 5 \mathrm{cM}$, confirmed suggestive linkages in the NIMH families on the CRIs located at $6 \mathrm{q} 27,14 \mathrm{q} 22$, and 11q25. The MLS scores for each CRI increased from the original scan and narrowing of the CRIs is also observed. Because of the likelihood of genetic heterogeneity in this complex disease, the heterogeneity LOD (HLOD) score statistic [31], which allows for linked and unlinked families in the sample, was performed on the original CIDR marker set and the follow-up set of markers in each region. In addition, the information content (IC), calculated in Genehunter Plus, for the CRI at $6 \mathrm{q}, 14 \mathrm{q}$ and $11 \mathrm{q}$ increased from a range of $0.30-0.54,0.39-0.52$, $0.32-0.52$ in the original scan to $0.44-0.65,0.45-0.62$, 0.43-0.65 in the follow up, respectively. An IC estimate close to 0.7 is the theoretical maximum for sib pair families, which is the predominant structure in the NIMH families [32]. It is also worthwhile to mention that the chr. 14 'peak' is located at a good distance away from the most obvious candidate gene in the region, i.e. PSEN1. Hence, the above data and analyses suggest these regions may harbor additional loci impacting on risk to $\mathrm{AD}$.

The reduced evidence for linkage at 3p26, initially identified as suggestive on the original genomic scan, may be attributed to confounding factors such as genetic or clinical heterogeneity of the disease, difficulty to detect genes of small effect, which reflects the difficulties and challenges that face the genetic mapping of complex traits like $\mathrm{AD}$, or it may be a true false positive.

\subsection{Classical gene discovery approach}

In general, gene discovery for complex traits follows four strategic steps: whole genome linkage or association studies to identify chromosome candidate regions, fine-mapping by linkage or association studies of polymorphisms (Ex. SNPs) to identify the putative causal gene(s), sequence analysis of the pinpointed gene (s) to identify causal variant(s), and finally functional tests of the found variants [33]. However, it is becoming apparent that many, and perhaps most of the regions that 
show linkage to a phenotype in multiple populations harbor more than one susceptibility locus [34]. For example, different asthma-related phenotypes are known to map to different locations within a broad linkage region [35]. Moreover, it is even likely that additional susceptibility loci reside within the same linkage peak and close to some of the positionally cloned genes, as has been shown for asthma [36]. Therefore, we propose that such regions are more likely to harbor multiple susceptibility loci, each with relatively small to moderate effects rather than large effects, on disease risk.

\subsection{Limitations of the classical approach}

The challenge in following-up linkage signals is to identify the genes that are responsible for the observed linkage results contained in such broad chromosomal regions (30 to $40 \mathrm{cM}$ of recombination or 30-40 millions of DNA bases in length). Fine mapping of the linked region using more closely spaced STRs is limited by the low frequency of recombination events between any two closely spaced points in the genome and the limited number of highly informative STRs available, resulting in only marginal increases in IC.

If a CRI has been confirmed and narrowed with follow-up mapping, the region still may be relatively broad, perhaps 20-30 cM, such that potentially hundreds of genes may be contained within a single CRI. Traditionally, the 1-LOD-drop support interval flanking the peak MLS is used as a guide to define the critical region of an observed linkage peak [31], which could further narrow the region from 5-15 cM. However, a large number of genes may still be located in this narrowed region. Given current technology, an exhaustive analyses of all these genes is possible, however given current resources, comprehensive evaluation of all of the genes in a region of linkage is rarely possible, being both laborious and expensive. For example, the CRIs on chromosomes $6 \mathrm{q} 27,14 \mathrm{q} 22$, and $11 \mathrm{q} 22$ that we confirmed and narrowed to intervals of $52 \mathrm{cM}, 40 \mathrm{cM}$, and $31 \mathrm{cM}$, respectively, still contain 159, 198, and 83 genes, respectively, according to the latest assembly (March 2006, NCBI build 36.1) of the human genome draft. Thus, a bioinformatics approach for identification and prioritization of candidate genes from the number of genes in confirmed CRIs remains a critical step following this classical approach. New approaches such as the current high-density genome-wide association (GWA) arrays also requires deep-sequencing, and if there are several SNPs in LD, then bioinformatics will help prioritize the genes to start deep sequencing on. GWA should be also considered as an initial step in the elucidation of susceptibility variants. There may be several regions that may harbor genetic variants that influence susceptibility to a specific disease. Several of the associated SNPs may fall within and near genes. Fine-mapping studies of these several regions are needed to confidently localize the signals to specific genes. Confirmation of the role of genes in the identified regions of interest will require prioritization of the genes and replication studies in other populations, and, ultimately, functional studies. More over, genome-wide association studies are promising, yet not always economically feasible or statistically desirable [37]. Therefore, one of the greatest challenges in disease association study design remains the intelligent selection of candidate genes.

\subsection{Selection of candidate genes within CRI}

There are potentially hundreds of potential candidate genes which could be investigated in association studies, family-based or case-control, using SNPs and programs such as LAMP [38] can be used to determine whether the entire linkage signal can be explained by a SNP. However, which candidate gene(s) to perform SNP genotyping for association testing is a conundrum. Hence, we must rely on the selection of positional candidate genes in the linkage region that have a known biological function related to our trait or are homologous to other genes in our phenotypic causal pathways. Combining mapping and arraying has been suggested as one approach to reduce the number of genes from QTL regions [39].

In the past few years, several groups have published bioinformatics methods for narrowing the lists of candidate genes (see the review by Tiffin et al. [34]. The fundamental assumption of the scheme for prioritizing candidate genes from linkage studies is that genes involved in or predisposing to a given polygenetic disease tend to share more commonalities in their molecular function, biological process or physiological pathway $[40,41]$ than genes chosen at random or genes not involved in the same disease. Hence, Gene Ontology annotation terms will be enriched among genes linked to the trait [42] and such commonalities are often sufficient to identify these genes from regions containing hundreds of other genes.

Based on these assumptions, one way to narrow the list of candidate genes in $\mathrm{AD}$ is to search for annotation terms that are enriched among the systematic metaanalyzed AD candidate genes, that have been confirmed 
by at least three case-control samples and cataloged in the "AlzGene database" as potential Alzheimer disease susceptibility genes (http://www.alzgene.org) relative to randomly sampled AD genes. Using these more biologically plausible GO function and process terms, we were able to reduce the number of positional candidate genes within each critical region (within the 1-LOD intervals) defined above. The list of genes can be initially prioritized based upon the number of GO terms assigned to each gene. Nevertheless, a large number of genes in the human genome are uncharacterized or poorly characterized, and the annotation of genes in Gene Ontology (GO) databases are incomplete and biased toward highly studied genes; thus, novel or poorly characterized genes could be missed. Moreover, GO is one approach and component to a more comprehensive systems biology approach. Additional sources of information such as gene expression, protein-protein interaction networks, tissue specificity, KEGG or BioCarta pathways, and sequence homology, could be integrated into a combined statistic, and biological confirmation of the candidate genes should be performed. Although the approach here still suffers from the bias introduced by pathways selected by biased researchers [30,43,44], this bias will be reduced once more genome wide association studies are incorporated into the AlzGene database, and gene annotation becomes more comprehensive. Finally, each investigator can then develop bioinformatics methods for further narrowing or prioritizing the list of candidate genes using a variety of selection variables such as expression profiles in neuronal tissue, the number of GO terms for each gene, evolutionary conservation, and patterns of gene duplication [33], and other systems biology approaches to determine which to interrogate first.

\section{Conclusion}

In 2003, we reported the results of a whole genome AD linkage study in the NIMH AD Genetics Initiative families [1]. In this study, we performed a follow up linkage study by genotyping 24 additional STR markers in the same sample of 437 families. The chromosome $6 \mathrm{q} 27,14 \mathrm{q} 22,11 \mathrm{q} 27$ and 3p26 CRIs were statistically analyzed under the same dominant inheritance model, resulting in confirmatory evidence for the CRIs at $6 q 27,14 q 22$, and $11 q 27$. We were able to reduce the total number of genes in these regions to a list of plausible candidate genes using function and process GO terms derived from 24 meta-analyzed and confirmed
AD genes on the Alzgene website. The approach, using bioinofrmatics tool and databases like Alzgene will facilitate in the identification and prioritization of candidate genes after the classical follow-up of promising linkage region and for deep-sequencing of several SNPs that are in LD in the current high-density genome-wide association array platforms.

\section{Outlook of the experiment}

Due to the evidence of linkage and the consistency of signals, we will be pursuing chromosome regions $6 q 27,14 q 22$, and 11q25 for possible candidate genes. We plan to first, undertake detailed fine mapping of these CRIs using dense SNPs selected from HapMap to narrow down the CRIs through linkage disequilibrium (LD) mapping. We will include in this phase the interrogation of candidate genes using tag SNPs from HapMap. We plan to priortize these genes based on the number of GO terms for each, and expression in neuronal tissue and determine which to interrogate first. Selection of SNPs in candidate genes will be based upon the location (coding/promoter vs. non-coding SNPs), type (if coding) (nonsynonymous vs. synonymous), as well as comparison with other species [45, 46] to identify highly conserved variants. Finally, sequencing within critical gene regions will need to be done in a systematic way to identify gene variants that may predispose to AD. These can then be confirmed in population-based studies, with further studies in animal models or other in vivo methods to ascertain its function in the disease process.

\section{Acknowledgements}

The authors would like to thank Micah Simmons for his technical support. The authors are extremely grateful to the families whose participation made this work possible. This work was supported by a grant from the NIMH (R01 NS045934-05).

\section{References}

[1] D. Blacker, L. Bertram, A.J. Saunders, T.J. Moscarillo, M.S. Albert, H. Wiener, R.T. Perry, J.S. Collins, L.E. Harrell, R.C. Go et al., Results of a high-resolution genome screen of 437 Alzheimer's disease families, Hum Mol Genet 12(1) (2003), 23-32. 
[2] R.T. Perry, H. Wiener, L.E. Harrell, D. Blacker, R.E. Tanzi, L. Bertram, S.S. Bassett and R.C. Go, Follow-up mapping supports the evidence for linkage in the candidate region at 9q22 in the NIMH Alzheimer's disease Genetics Initiative cohort, Am J Med Genet B Neuropsychiatr Genet 144B (2007), 220-227.

[3] D.T. Selkoe, Alzheimer's disease: genes, proteins, and therapy, Physiol Rev 81 (2001), 741-766.

[4] R. Guttman, R.D. Altman and N.H. Nielsen, Alzheimer disease. Report of the council on scientific affairs, Arch Fam Med 8(4) (1999), 347-353.

[5] A. Lobo, L.J. Launer, L. Fratiglioni, K. Andersen, A. Di Carlo, M.M. Breteler, J.R. Copeland, J.F. Dartigues, C. Jagger, J. Martinez-Lage, H. Soininen and A. Hofman, Prevalence of dementia and major subtypes in Europe: A collaborative study of population-based cohorts. Neurologic Diseases in the Elderly Research Group, Neurology 54 (2000), S4-S9.

[6] R.F. Itzhaki and M.A. Wozniak, Herpes simplex virus type 1, apolipoprotein E, and cholesterol: a dangerous liaison in Alzheimer's disease and other disorders, Prog Lipid Res 1 (2006), 73-90.

[7] R.E. Tanzi, A genetic dichotomy model for the inheritance of Alzheimer's disease and common age-related disorders, J Clin Invest 104(9) (1999), 1175-1179.

[8] R. Sherrington, E.I. Rogaev, Y. Liang et al., Cloning of a gene bearing missense mutations in early-onset familial Alzheimer's disease, Nature 375 (1995), 754-760.

[9] E. Levy-Lahad, W. Wasco, P. Poorkaj et al., Candidate gene for the chromosome 1 familial Alzheimer's disease locus, Science 269 (1995), 973-977.

[10] A. M.Goate, M.-C. Chartier-Harlin, M.C., Mullan et al., Segregation of a missense mutation in the amyloid precursor protein gene with familial Alzheimer's disease, Nature 349 (1991), 704-706.

[11] N. Ertekin-Taner, Genetics of Alzheimer's disease: a centennial review, Neurol Clin 25(3) (2007), 611-667.

[12] A.D. Roses, A model for susceptibility polymorphisms for complex diseases: apolipoprotein E and Alzheimer disease, Neurogenetics 1(1) (1997), 3-11.

[13] A.J. Slooter, M. Cruts, S. Kalmijn, A. Hofman, M.M. Breteler, C. Van Broeckhoven and C.M. van Duijn, Risk estimates of dementia by apolipoprotein E genotypes from a populationbased incidence study: the Rotterdam Study, Arch Neurol 55(7) (1998), 964-968.

[14] M.L. Hamshere, P.A. Holmans, D. Avramopoulos, S.S. Bassett, D. Blacker, L. Bertram, H. Wiener, N. Rochberg, R.E. Tanzi, A. Myers, V.F. Wavrant-De, R. Go, D. Fallin, S. Lovestone, J. Hardy, A. Goate, M. O'donovan, J. Williams and M.J. Owen, Genome-wide linkage analysis of 723 affected relative pairs with late-onset Alzheimer's Disease, Hum Mol Genet (Aug 27, 2007), Epub ahead of print.

[15] L. Bertram and R.E. Tanzi, The current status of Alzheimer's disease genetics: what do we tell the patients? Pharmacol Res 50(4) (2004), 385-396.

[16] A.S. Khachaturian, C.D. Corcoran; L.S Mayer, P.P Zandi and J.C.S Breitner, Apolipoprotein E 4 Count Affects Age at Onset of Alzheimer Disease, but Not Life time Susceptibility: The Cache County Study, Arch Gen Psychiatry 61 (2004), 518524.

[17] M.I. Kamboh, Molecular genetics of late-onset Alzheimer's disease, Ann Hum Genet 68 (2004), 381-404.

[18] P. Kehoe, F. Wavrant-De Vrieze, R. Crook, W.S. Wu, P. Holmans, I. Fenton, G. Spurlock, N. Norton, H. Williams, N.
Williams et al., A full genome scan for late onset Alzheimer's disease, Hum Mol Genet 8(2) (1999), 237-245.

[19] M.A. Pericak-Vance, J. Grubber, L.R. Bailey, D. Hedges, S. West, L. Santoro, B. Kemmerer, J.L. Hall, A.M. Saunders, A.D. Roses et al., Identification of novel genes in late-onset Alzheimer's disease, Exp Gerontol 35(9-10) (2000), 13431352.

[20] A. Myers, F. Wavrant De-Vrieze, P. Holmans, M. Hamshere, R. Crook, D. Compton, H. Marshall, D. Meyer, S. Shears, J. Booth et al., Full genome screen for Alzheimer disease: stage II analysis, Am J Med Genet 114(2) (2002), 235-244.

[21] A. Sillen, C. Forsell, L. Lilius, K. Axelman, B.F. Bjork, P. Onkamo, J. Kere, B. Winblad and C. Graff, Genome scan on Swedish Alzheimer's disease families, Mol Psychiatry 11(2) (2006), 182-186.

[22] L. Bertram, M.B. McQueen, K. Mullin, D. Blacker and R.E. Tanzi, Systematic meta-analyses of Alzheimer disease genetic association studies: the AlzGene database, Nat Genet 39(1) (2007), 17-23.

[23] J.H. Lee, Mayeux, R. Mayo, D. Mo, J. Santana, V. Williamson, J. Flaquer, A. Ciappa, A. Rondon, H. Estevez et al., Fine mapping of 10q and 18q for familial Alzheimer's disease in Caribbean Hispanics, Mol Psychiatry 9 (2004), 1042-1051.

[24] G. McKhann, D. Drachman, M. Folstein et al., Clinical diagnosis of Alzheimer's disease: report of the NINCDS-ADRDA work group under the auspices of the Department of Health and Human Services Task Force on Alzheimer's disease, Neurol 34 (1984), 939-944.

[25] M.C. Tierney, R.H. Fisher, A.J. Lewis, M.L. Zorzitto, W.G. Snow, D.W. Reid and P. Nieuwstraten, The NINCDS-ADRDA Work Group criteria for the clinical diagnosis of probable Alzheimer's disease: a clinicopathologic study of 57 cases, Neurology 38(3) (1988), 359-364.

[26] J.S. Collins, R.T. Perry, B. Watson, L.E. Harrell, R.T. Acton, D. Blacker, M.S. Albert, R.E. Tanzi, S.S. Bassett, M.G. McInnis, R.D. Campbell and R.C. Go, Association of a haplotype for tumor necrosis factor in siblings with late-onset Alzheimer disease: the NIMH Alzheimer Disease Genetics Initiative, Am J Med Genet 96 (2000), 823-830.

[27] A. Kong and N.J. Cox, Allele-sharing models: LOD scores and accurate linkage tests, Am J Hum Genet 61(5) (1997), 1179-1188.

[28] L. Kruglyak, M.J. Daly, M.P. Reeve-Daly and E.L. Lander, Parametric and nonparametric linkage analysis: a unified multipoint approach, Am J Hum Genet 58 (1996), 1347-1363.

[29] S.A.G.E., Statistical analysis for genetic epidemiology. Version 5.0. (2002) Cork: Statistical Solutions Ltd.

[30] M.P. Mattson, Pathways towards and away from Alzheimer's disease, Nature 430(7000) (2004), 631-639.

[31] J.D. Terwilliger and J. Ott, Handbook of Human Genetic Linkage, Baltimore: Johns Hopkins University Press, 1994, 320.

[32] D.M. Evans and L.R. Cardon, Guidelines for genotyping in genome-wide linkage studies: Single-nucleotidepolymorphism maps versus microsatellite maps, Am J Hum Genet 75(4) (2004), 687-692.

[33] E. Lander and L. Kruglyak, Genetic dissection of complex traits: guidelines for interpreting and reporting linkage results, Nat Genet 11(3) (1995), 241-247.

[34] S. Hoffjan and C. Ober, Present status on the genetic studies of asthma, Current Opinion in Immunology 14 (2002), 709-717.

[35] B.A. Raby, E.K. Silverman, R. Lazarus, C. Lange, D.J. Kwiatkowski and S.T. Weiss, Chromosome 12q harbors multiple genetic loci related to asthma and asthma-related phenotypes, Hum Mol Genet 12 (2003), 1973-1979. 
[36] E. Noguchi, Y. Yokouchi, J. Zhang, K. Shibuya, A. Shibuya and M. Bannai, Positional identification of an asthma susceptibility gene on human chromosome 5q33, Am J Respir Crit Care Med 172 (2005), 183-188.

[37] D. Thomas, Are we ready for genome-wide association studies? Cancer Epidemiol Biomarkers Prev 15 (2006), 595-598.

[38] M. Li, M. Boehnke and G. R. Abecasis, Joint modeling of linkage and association identifying SNPs responsible for a linkage signal, Am J Hum Genet 76(6) (2005), 934-949.

[39] M.L. Wayne and L.M. McIntyre, Combining mapping and arraying: An approach to candidate gene identification, Proc Natl Acad Sci USA 99(23) (2002), 14903-14906.

[40] N. Tiffin, E. Adie, F. Turner, H.G. Brunner et al., Computational disease gene identification: a concert of methods prioritizes type 2 diabetes and obesity candidate genes, Nucl Acids Res 34 (2006), 3067-3081.
[41] T. Toyoda and Y. Takigawa, Selection of Candidate Genes for Polygenic Diseases by Utilizing Protein-Protein Interaction Networks, Genome Informatics 11 (2000), 286-288.

[42] F.S. Turner, D.R. Clutterbuck and C.A. Semple, POCUS: mining genomic sequence annotation to predict disease genes, Genome Biology (2003), 4:R75.

[43] M. Blurton-Jones and F.M. Laferla, Pathways by which Abeta facilitates tau pathology, Curr Alzheimer Res 3(5) (2006), 437-448.

[44] M. Goedert and M.G. Spillantini, A century of Alzheimer's disease, Science 314(5800) (2006), 777-781.

[45] C. Ferrer-Costa, M. Orozco and X. de la Cruz, Use of bioinformatics tools for the annotation of disease-associated mutations in animal models, Proteins 61 (2005), 878-887.

[46] K.M. Weiss, In search of human variation, Genome Res 8 (1988), 691-697. 


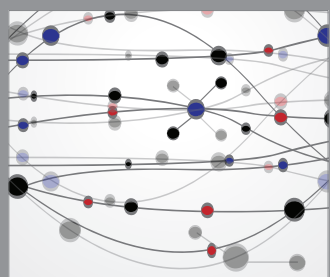

The Scientific World Journal
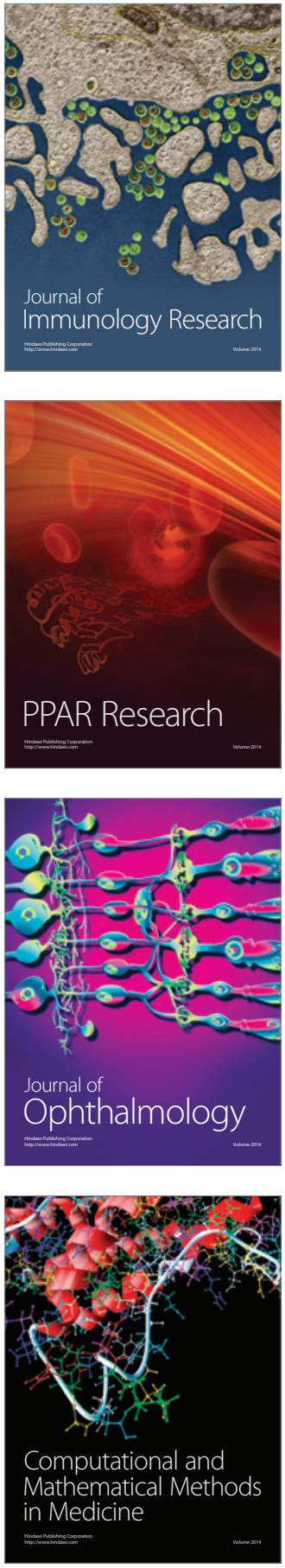

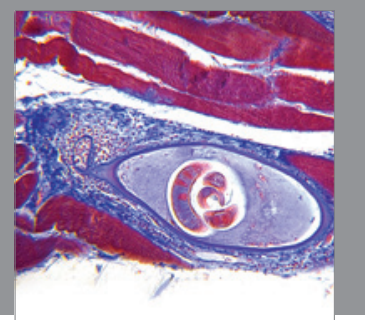

Gastroenterology

Research and Practice
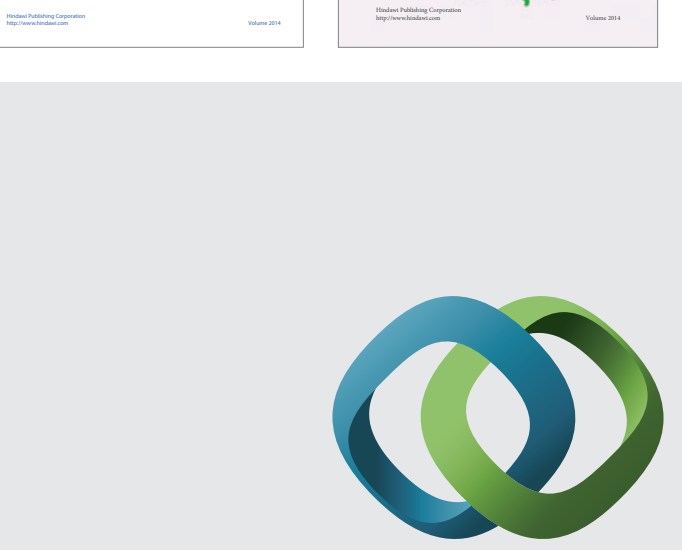

\section{Hindawi}

Submit your manuscripts at

http://www.hindawi.com
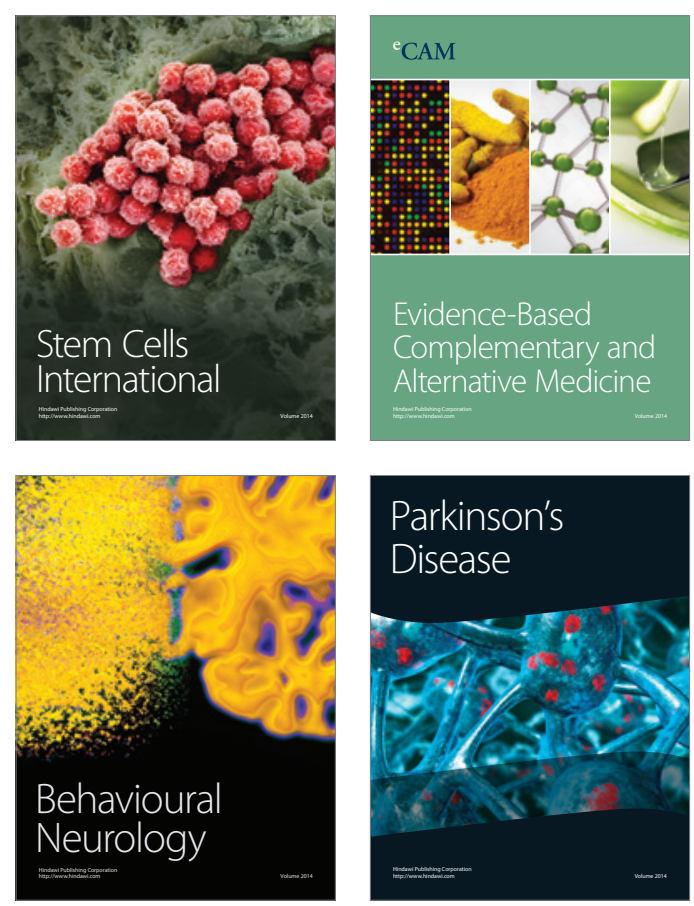

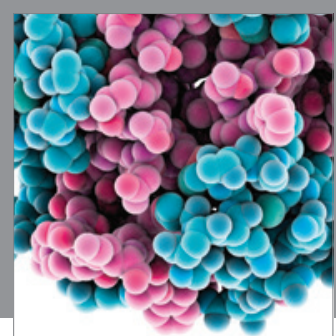

Journal of
Diabetes Research

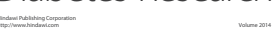

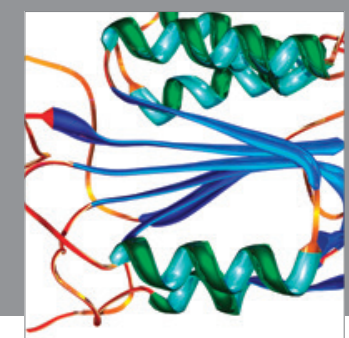

Disease Markers
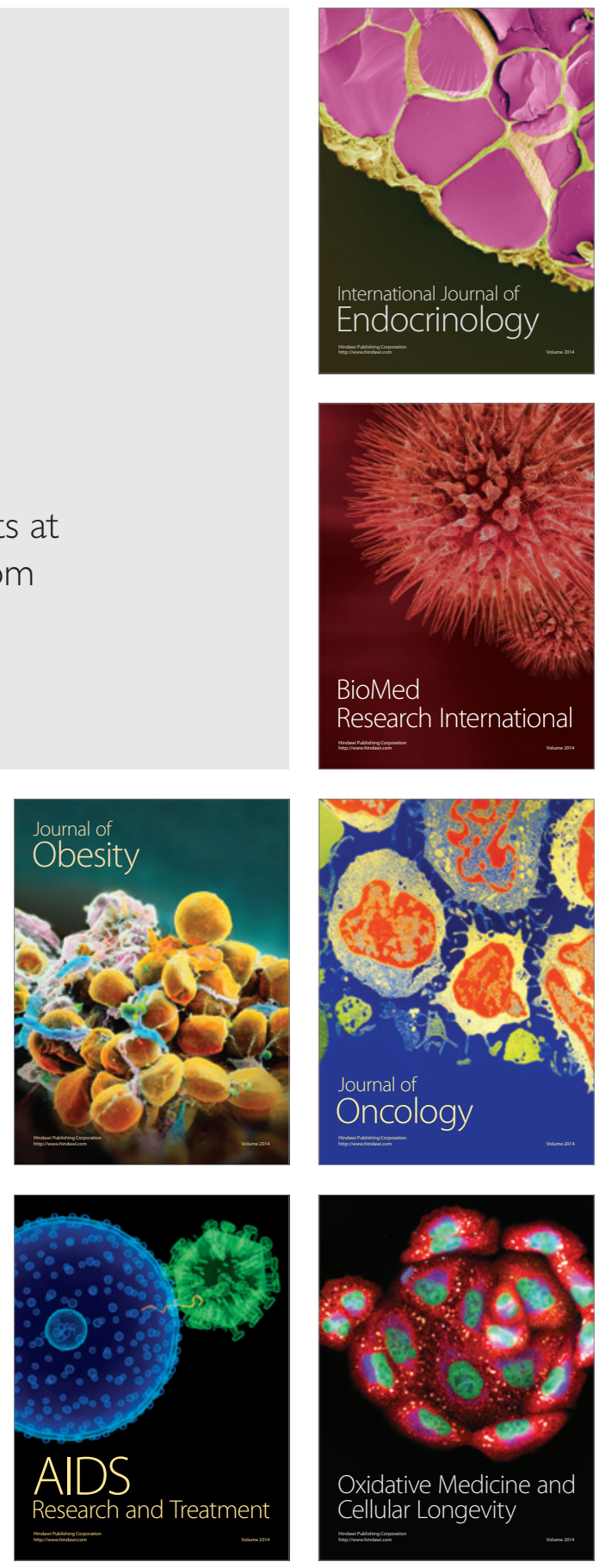